\title{
Bollywood Movies and Social Media Analytics \\ ${ }^{1}$ Dr. Gayathri Band, ${ }^{* 2}$ Dr. Ruchi Sao
${ }^{1,2}$ Assistant Professor, Department of Management Technology, RCOEM, Nagpur \\ Email:bandgs@rknec.edu
}

\section{Received: 09 ${ }^{\text {th }}$ July 2018, Accepted: $14^{\text {th }}$ August 2018, Published: $3^{\text {st }}$ August 2018}

\begin{abstract}
There is a lot of usage of data available on social media for analysis in corporate sector today. The research paper is based on literature available through secondary data. It highlights the use of social media for creating awareness and a positive feeling for Bollywood movies. For the purpose of the paper, three major movies released in India in the past two years have been taken as a sample in which social data analytics has been used by the production houses. The movies are 'Golmaal again', 'Ae dil hain mushkil' and 'Bahubali'. Majority of the end users at social networking sites share their preferences and interests with respect to the field of art, movies, travel or any other criteria. This data is shared by the social networking sites of the companies with whom they have a contract. For instance, if I see a video on Facebook, similar videos start showing up in my news feed. The production houses have taken this as an opportunity by launching contests, sharing unplugged songs and more initiatives discussed in the paper which has helped to create more number of viewers and in turn more number of the audience waiting for the movie. Through this paper, techniques and ideas used by capturing the social media have been written.
\end{abstract}

Keywords: Bollywood Movies, Hash Tag, Social Media Analytics

\section{Introduction}

We live in an era of technology where our information is in open access, thanks to social networking sites and the umpteen number of android apps that we keep downloading. Social media also encompasses Really Simple Syndication (RSS) feeds, blogs, wikis and news which generates the unstructured text; can be accessible through the web (Batrinca B \& Treleaven P, 2014). There are many terms used such as news analytics, opinion mining, scraping, sentiment analysis, text analytics, data visualization and so many more which are now used for social media data analytics.

Today, we have a profile page which sneaks into our taste, lifestyle and all preferences. This data is being used from social media in the field of analytics to a great extent now. So, if I am interested in movies that are made by Rohit Shetty, Bollywood director; I would start getting newsfeed on the same on my profile page. Be the category of movie action, adventure, documentary or any other type; attracting the audience is very common by applying tools of data analytics. It is now very common for production houses who hire an expert team of social media analytics to pull the audience. The experts would help you to build a brand for the movies. They identify the areas and the generations which would get attracted to the movies on the basis of which advertising and campaigning plans are made.

Users of social media are ready to share the data and the experts of social media analytics are happily ready to use the same to increase the profits of the production houses. Moreover, as there are different types of movies right from a small and new star cast to a blockbuster one. I still remember watching at trailer of a local language Marathi movie in India by the name 'Aapla Manus' which was shown in the social feed of those users who have put Marathi movies as their interest. The movies with a small budget are using it as a useful tool to attract the audience and use it as a smart social media data tool.

The marketing team can no more survive by using only the age old principles of marketing. It is now time to use data analytics to make the audience stay tuned for updates on the movies. Social media managers team up with the marketing department to cater to the needs of entertainment. So when Dabang or Bahubali was about to release, android games were developed. Statistics were taken as to how many users downloaded the version. Trailers were uploaded on you tube and other channels to see the number of views. Within hours, millions of people downloaded and started to like and share the videos.

The price of movie tickets is rising and so is the experience of watching a movie with a tub of popcorn and coke. So, the audience is more concerned about knowing about the movie before they spend around 700 per person. The same has been understood by the production houses and data analytics firms also. Thus, the hash tag phenomena gained impetus. Brand partnerships started. So, the entire look and collection of the leading star cast is available at Jabong or Myntra shopping sites.

Contests are organized online where the audience has to share their stories and hash tag the name of the movie and the event. Various social networking sites used are facebook, twitter, you tube, instagram and so many more. Best stories shared gets a prize like a date with the lead star of the movie. There are contests in 
which free movie tickets are given. The number of shares and the posts on timelines with the hash tag feature further helps in promotion of brand. These strategies are majorly used to keep the audience engaged and well-connected even prior to the release date. Today, liking and sharing is now more popular and trending than word of mouth.

Thus, the opportunity and challenge is the same: 'Bridging the gap between business metrics and efforts taken by social media' (Gabie Kur, 2014). Tools such as Brandwatch, Buffer, Google analytics, HootSuite and so many more are being used by experts to boost revenue.

\section{Results and Discussions}

Discussion on two movie case analysis which used social media for promoting the movie and the results of social media analytics show the buzz generated and their respective box office collection created by keeping social media at core of their marketing strategies.

An unprecedented buzz was generated around the movie as the Golmaal Again marketing strategy was created keeping social media at core. The objective of the strategy was leveraging the popularity of the Golmaal franchise among its loyal fan base and combining it with the far reaching capabilities of social media, the makers of the film intended to create an unprecedented buzz around its release and turn it into one of the biggest blockbuster of the year.

The social media promotion included events where participants were required to include the hashtags \#GolmaalAgain, \#GolmaalAgainTrailer and \#GolmaalAgainTrailerInvite, across all social media platforms to win a chance to attend the trailer launch. The team also leveraged the social media popularity of the cast by cross posting the Golmaal Again trailer through their social media accounts. It ensured the trailer reached the maximum number of people.

In the next phase of social media activity, Twitter was chosen as the platform of choice as the official Golmaal Again, T-Series and singer Amaal Malik's Twitter accounts indulged in a conversation to promote the song Hum Nahi Sudhrenge from the movie. Post the release of the film, fan reaction videos from Dubai, India, and other parts of the world were consistently leveraged across all social media platforms to spread the positive word of mouth. Also, a short Facebook Live video of the star cast carrying out a surprise visit to a cinema hall was broadcasted.

All such initiatives and strategies made The Golmaal Again trailer became the third most shared Bollywood film trailer on Facebook for 2017 with a total share count of 45,375 shares in over a month. The trailer also garnered more than 20 million views within 24 hours. \#GolmaalAgain trended on Facebook for 48 hours and the official film handles have crossed more than $10.8 \mathrm{~K}$ followers on Twitter and $13.3 \mathrm{~K}$ followers on Instagram. On Twitter, \#GolmaalAgain was trending for 6 hours and it trended in Mumbai for more than 10 hours. The trailer for the film also trended on top on YouTube for four days, and the Facebook Live video of the cast greeting cinemagoers managed to get a total reach of $17.9 \mathrm{~K}$. Through these social media activities and exercises, Golmaal Again successfully created a widespread intrigue and curiosity around its release which helped the movie become one of Bollywood's highest grossing movies in 2017.

Another movie released in Bollywood was 'Ae dil hain mushkil'. The strategy adopted by Dharma productions for the movie was to create curiosity for the movie through social media. The contests were launched and the viewers had to hash tag ADHM. The contest was about reconnecting with special friends in life and sharing stories which would result in knowing the importance of relationship based on the theme of the movie. Within a day, millions of people tagged ADHM thereby creating further interest in the movie. The star cast already had a huge fan following. The apparels worn by the star cast were created by brands such as Numero Uno which further created a stir amongst youngsters to look and dress up like the star cast. Style partner; Numero Uno also launched a contest where a lucky customer will get a chance to meet the lead star cast, Ranbir Kapoor himself.

The social data analytics team made sure that the feed is directly linked to the preferences given on the Facebook page of the users. Instagram, twitter and Facebook was used to release unpublished songs of small durations.

These initiatives were to attract fans and audience to the movie. Within a short span of time, millions of audience were attracted and continued to remain engaged due to these strategies. The production company along with a team of experts from marketing and social media analytics made sure that the story telling which started before four months of the release created a feeling of excitement amongst the young generation.

The sales had crossed $108 \mathrm{Cr}$ in India and in overseas, the total collection reached $\$ 11.7$ Million by third week. The total overseas box office collection was 8.2 million USD which came as the second highest in the overseas market.

'Baahubali' is an Indian epic-historical fiction film filled with oodles of drama, action and visual art. Right from the onset, the chief people linked with this project had a clear vision to have a massive pan-India 
release for the franchise. They wanted to make a national film, instead of letting it stay restricted only to regional languages like Telugu and Tamil. As part of their promotional maneuvers, they announced a unique phone number $(+918096755222)$ to give exclusive updates about the film to their fans who registered for the same, on 27th December 2014. They ran various campaigns on $\mathrm{FB}$ be it the 'Baahubali Profile Picture Frame' contest, broadcasting 'Live' on Facebook by offering titbits about the film or the 'Baahubali Comics' using Facebook canvas (immersive and interactive mobile ad-experience purpose), each idea generated a lot of buzz. One of the noted campaigns was the launch of Baahubali-themed animated stickers inside FB Messenger app, which saw a sudden spike in its downloads within a week. Their official Facebook page has a fan base of more than 4.21 million people. Their team unveiled short 'Making-of' and 'Behindthe-scene' videos on their official YouTube channel, sporting the film's lead actors and actresses on their respective birthday occasions. This plainly kept the audience on their toes, every other month. Their team even ran 'Baahubali Quest' Twitter campaigns by cleverly asking their followers to follow the cast \& crew's social media profiles by using the hashtag \#ADayWithBaahubali, in order to win lucky tickets for the movie. The film's official Twitter handle has slightly more than $576 \mathrm{~K}$ followers. The mimic question “Why Kattappa Killed Baahubali?" grabbed the humongous attention of viewers on national and international platforms alike. In less than no time, the hashtag \#WKKB went viral on social media platforms. The results are record breaking as well:

(a) Record-breaking movie 'Baahubali: The Beginning', the first installment in this movie series grossed a whopping ₹600 crore worldwide.

(b) In India, 'Baahubali: The Beginning' became the fourth Facebook's most talked-about topic of the year 2015, after PM Narendra Modi, E-commerce Boom and late president A.P.J. Abdul Kalam.

(c) 'Baahubali: The Beginning' topped the Google (India) 'Trending Movies' list of the year 2015 and also secured the second position in Google (India) 'Trending Searches' list of the year 2015.

(d) The official trailer of 'Baahubali 2: The Conclusion' gained 59.8 million views within first 24 hours across the world (YouTube, Facebook and Twitter platforms combined), when it released online on 16th March 2017.

\section{Conclusion}

The simple accessibility of APIs given by Twitter, Facebook and News administrations has prompted a 'blast' of information administrations and programming apparatuses for scratching and estimation investigation, and online networking examination stages. The contextual analyses introduced in this paper delineate the breadth and capability of online networking examination. A considerable measure of difficulties still exists in the online networking examination field. As large information have risen as another logical worldview, growing more viable and effective enormous information methods for webbased social networking investigation and utilize these strategies to make new esteem or help with settling on more educated choices in huge information condition has turned out to be progressively essential.

\section{References}

1. J. Vignesh, "Data analytics makes a debut in Bollywood",https://tech.economictimes.india times.com/news/technology/data-analyticsmakes-a-debut-in-bollywood/61776061

2. Batrinca B, Treleaven P, "Social media analytics: a survey of techniques, tools and platforms", Springer Publications, July 2014, pp $89-116$

3. Ankit Shukla, http://in7h.com/drishyam-dataanalytics/, August 2015

4. Gabie Kur, https://www.techradar.com/news/software/bu siness-software/10-socia 1-analyticscompanies-yo u-need-to-know-1251715, 2014

5. https://www.digitalvidya.com/blog/howfacebook-influences-mo vie-promotion-andit s-success/

6. https://www.digitalvidya.com/blog/11social-media-marketing-ideas-used-bybaahubali-mo vie-franchise/ 